\title{
Heat and Drought Influence Photosynthesis, Water Relations, and Soluble Carbohydrates of Two Ecotypes of Redbud (Cercis canadensis)
}

\author{
Jason J. Griffin'1, Thomas G. Ranney², and D. Mason Pharr³ \\ Department of Horticultural Science, North Carolina State University, Raleigh, NC 27695-7609
}

\begin{abstract}
AdDITIONAL INDEX WORDS. high temperature stress, ononitol, osmotic adjustment, D-pinitol, polyol, water deficit stress
Abstract. Net photosynthesis (Pn) of two ecotypes of redbud (Cercis canadensis L.) was studied following growth under high temperatures and increasing drought. Although mexican redbud $[C$. canadensis var. mexicana (Rose) $M$. Hopkins] exhibited greater Pn than eastern redbud (C. canadensis var. canadensis $L$.), Pn decreased at a similar rate under water deficit stress for both ecotypes. Mexican redbud also had greater instantaneous water use efficiency [net photosynthesis : transpiration (WUE)] than eastern redbud. Differences in both Pn and WUE might have been due to differences in leaf thickness. The optimum temperature for potential photosynthetic capacity $\left(37^{\circ} \mathrm{C}\right)$ was unaffected by irrigation or ecotype. Tissue osmotic potential at full turgor was more negative in eastern redbud, but was unaffected by drought stress in either ecotype. Soluble carbohydrate content was higher in eastern redbud, and in both ecotypes, D-pinitol was the major soluble carbohydrate and was considerably more abundant in the water-stressed plants. Total polyol content (myo-inositol + ononitol + pinitol) was also greater in the water-stressed plants. Both ecotypes were very tolerant of high temperatures and drought.
\end{abstract}

Plants are frequently exposed to a variety of environmental stresses that occur simultaneously such as drought and high temperature. The additive and interactive effects of these stresses and the ability of a plant to resist multiple stresses simultaneously can be an important factor in plant growth and survival in stressful environments (Lichtenthaler, 1996).

Water deficit can trigger a variety of plant responses. One of the more immediate responses is a reduction of stomatal aperture (Dubey, 1997) that results in decreased photosynthesis and limits the evaporative cooling potential of the leaf. In general, net photosynthesis (Pn) decreases while leaf temperature increases during a drought event. Many plants are capable of osmotic adjustment through the accumulation of a variety of molecules whose concentrations have been positively correlated with increased turgor, stomatal conductance, transpirational cooling, Pn, and reduced leaf senescence (Berkowitz, 1998; Ranney et al., 1991; Thomas, 1997). Additionally, it has been suggested that the ability to acclimate and maintain positive Pn during a slowly developing drought is directly related to survival and recovery following a drought (Krüger and van Rensburg, 1995). Many of the molecules involved in osmotic adjustment, the polyols in particular, also have the potential to scavenge toxic reactive oxygen species (Guo and Oostrhuis, 1995; McManus et al., 2000; Popp and Smirnoff, 1995; Sheveleva et al., 1997; Smirnoff and Cumbes, 1989). Mannitol, for example, was very effective in scavenging reactive oxygen species when it was produced in the chloroplast of transgenic tobacco plants (Nicotiana tabacum L.) (Shen et al., 1997).

Received for publication 3 June 2003. Accepted for publication 9 Dec. 2003. This research was funded in part by the North Carolina Agricultural Research Service, Raleigh, NC 27695-7643. The authors wish to thank Tom Eaker for technical assistance, Bailey Nurseries Inc., St. Paul, Minn., for plant material, and Andreas Richter (Institute of Ecology and Conservation Biology, University of Vienna, Austria), for kindly providing the ononitol standard. From a thesis submitted by J.J.G. in partial fulfillment of the requirements for the $\mathrm{PhD}$ degree.

${ }^{1}$ Assistant professor, and corresponding author. Current address: Kansas State University, John C. Pair Horticultural Center, Haysville, KS 67060-8351.

${ }^{2}$ Professor, Mountain Horticultural Crops Research and Extension Center, Fletcher, NC 28732-9244.

${ }^{3}$ William Neal Reynolds Distinguished Professor
High temperatures can also inhibit plant growth and development. Elevated temperatures increase respiration and therefore require greater carbon fixation for sustained growth and survival. Temperatures $>35^{\circ} \mathrm{C}$ significantly decrease the activity of Rubisco (Crafts-Brandner and Law, 2000; Crafts-Brandner and Salvucci, 2000), thereby limiting photosynthesis. The capacity of a plant to acclimate and maintain photosynthesis under high temperatures is a critical factor in heat tolerance (Hale and Orcutt, 1987). This adaptation/acclimatization to temperature is considered one of the primary determinants of geographical distribution among agricultural crops (Mahan et al., 1997), and differs among closely related species native to regions with different climates (Berry and Björkman, 1980; Ranney and Peet, 1994; Ranney and Ruter, 1997).

When combined, drought and high temperature have both additive and interactive effects on plant growth (Stoyanova and Yordanov, 1999). Limited transpirational cooling exacerbates the effects of already high air temperature (Hale and Orcutt, 1987) by causing leaf temperatures to rise above the air temperature, making the plant more susceptible to photoinhibition (Biswal, 1997; Dubey, 1997; Falk et al., 1996).

Cercis canadensis var. canadensis (eastern redbud) and C. canadensis var. mexicana (mexican redbud) are two varietal ecotypes of redbud. Eastern redbud grows throughout the eastern half of the United States and is generally found as a mesic, understory species. Mexican redbud grows from southwestern Texas, south through central Mexico to Mexico City, and is typically found in more xeric environments. When seedlings from different geographical origins were compared, leaf morphological characteristics typically associated with xeric conditions (increased pubescence, thicker and smaller leaves, and fewer and smaller stomata) were found to increase in the western populations (Donselman and Flint, 1982). Therefore, the objectives of this study were to: determine if water deficit stress compromises the thermotolerance of photosynthesis in redbuds; evaluate whether or not this interaction varies by ecotype; and examine specific limitations and mechanisms that influence resistance to these stresses. 


\section{Materials and Methods}

Plant material and growing conditions. Two-year-old seedlings of eastern redbud and mexican redbud were purchased from commercial nurseries and planted in $38 \mathrm{~L}$ containers measuring $46 \mathrm{~cm}$ diameter and $30 \mathrm{~cm}$ tall (one of each ecotype per container). Container substrate was 4 pine bark : 2 peat : 1 perlite (by volume) amended with dolomitic limestone at 5.3 and 3 $\mathrm{kg} \cdot \mathrm{m}^{-3}$ micronutrients (Esmigran; The Scotts Co., Marysville, Ohio). Final substrate $\mathrm{pH}$ was 6.2. Shared containers were used to ensure root systems of both taxa in a given container experienced similar substrate conditions. Plants were grown in a glass greenhouse (minimum temperature $24{ }^{\circ} \mathrm{C}$ day $/ 21{ }^{\circ} \mathrm{C}$ night) and fertigated weekly with a complete water-soluble fertilizer [20N-8.3P-15K (Peters Peat-Lite, 20-19-18, The Scotts Co.)] at $100 \mathrm{mg} \cdot \mathrm{L}^{-1}$ actual $\mathrm{N}$ until treatment initiation. Additional irrigation was applied as necessary.

Plants were given 2 weeks to establish before greenhouse temperatures were raised to minimum $35^{\circ} \mathrm{C}$ day $/ 25^{\circ} \mathrm{C}$ night to acclimate all plants to high temperatures. Following a $21 \mathrm{~d}$ acclimation at this temperature regime, drought stress was initiated by withholding irrigation from half of the containers. At this stage all plants were healthy and growing rapidly. The large container volume and substrate composition ensured a gradual depletion of available water, simulating a natural drought and allowing for acclimation and uniform stomatal closure. A total of 14 seedlings per ecotype (seven drought stressed and seven well irrigated) were used throughout this study for the following measurements.

GaS EXCHANGE MEASUREMENTS AS A FUNCTION OF SUBSTRATE MOISTURE CONTENT. Pn and instantaneous water use efficiency (WUE) were measured on a $2-\mathrm{cm}^{2}$ area of leaf surface using an open portable gas exchange system (CIRAS-1; PP Systems, Haverhill, Mass). Data were collected by placing one recently matured leaf per plant in the cuvette at $30^{\circ} \mathrm{C}$, with an ambient $\mathrm{CO}_{2}$ concentration of $350 \mu \mathrm{L} \cdot \mathrm{L}^{-1}$, and exposed to photosynthetically active radiation $(P A R)$ of $2000 \mu \mathrm{mol} \cdot \mathrm{m}^{-2} \cdot \mathrm{s}^{-1}$. Measurements were taken on 14 leaves per ecotype between 10:00 and 13:00 HR. WUE was calculated as the ratio Pn : transpiration. Substrate water content was recorded in each container using a soil moisture probe (ThetaProbe, Dynamax, Houston, Texas) calibrated to substrate-specific water content. Probes were inserted horizontally into the root zone under each ecotype midway through the container profile.

TeMPERATURE RESPONSE OF PHOTOSYNTHESIS. When substrate moisture reached $2 \%$ to $5 \%$ (corresponding to a pre-dawn water potential of about $-2.0 \mathrm{MPa}$ ) plants were moved into the lab for data collection the evening before measurements were to be taken. Similar to the method of Ranney and Ruter (1997), potential photosynthetic capacity was determined by measuring Pn during increasing leaf temperature under saturating $\mathrm{CO}_{2}\left(2000 \mu \mathrm{L} \cdot \mathrm{L}^{-1}\right)$ and saturating $P A R\left(2000 \mu \mathrm{mol} \cdot \mathrm{m}^{-2} \cdot \mathrm{s}^{-1}\right)$. A recently matured leaf was placed in the cuvette at $20^{\circ} \mathrm{C}$ and allowed $20 \mathrm{~min}$ to stabilize before the first measurement was taken. The temperature was then raised in $5^{\circ} \mathrm{C}$ increments from 20 to $45^{\circ} \mathrm{C}$ with data collected at each temperature level following a $20 \mathrm{~min}$ acclimation period.

A/Ci ReSPonses. Following temperature response measurements, A/Ci responses (Pn as a function of increasing intercellular $\mathrm{CO}_{2}$ concentration) were measured on a separate leaf to detect stomatal and nonstomatal limitations to Pn of well-watered and drought-stressed plants. Again, a recently matured leaf was placed in the cuvette at a temperature of $30^{\circ} \mathrm{C}$ and $2000 \mu \mathrm{mol} \cdot \mathrm{m}^{-2} \cdot \mathrm{s}^{-1}$ $P A R$, and ambient $\mathrm{CO}_{2}$ at $350 \mu \mathrm{L} \cdot \mathrm{L}^{-1}$. The air within the cuvette was maintained at $\approx 70 \%$ relative humidity to minimize stomatal heterogeneity. Following a 20 min acclimation period, Pn was recorded and the $\mathrm{CO}_{2}$ concentration was reduced to $50 \mu \mathrm{L} \cdot \mathrm{L}^{-1}$ and another reading was taken. A gradual increase in $\mathrm{CO}_{2}$ to a final concentration of $1990 \mu \mathrm{L} \cdot \mathrm{L}^{-1}$ in 10 increments occurred with a reading taken at each increment following a $10 \mathrm{~min}$ acclimation period. Data were then fit to the exponential model used by Jacob et al. (1995) and adopted by Reid and Fiscus (1998):

$A=a\left(1-e^{-b C i}\right)+c$

where $a$ is the maximum rate of carbon assimilation, $b$ is the initial slope or carboxylation efficiency, and $c$ is the intercept on the ordinate.

LEAF OSMOLALITY. Leaf osmolality at full turgor was determined on expressed sap using the procedures of Ranney et al. (1991). Recently matured leaves were harvested early in the morning and re-hydrated by submerging the cut petioles in deionized water and covering the leaf blades with a polyethylene bag for $2 \mathrm{~h}$. It has been shown that this length of time does not over-hydrate the tissue (Evans et al., 1990). Each leaf was then placed in a 3 $\mathrm{mL}$ plastic syringe (one leaf per syringe) and frozen at $-80^{\circ} \mathrm{C}$. Upon removing the syringe from the freezer and allowing it to reach room temperature, sap was expressed by depressing the syringe. Osmolality of a $10-\mu \mathrm{L}$ sample of expressed sap solution was determined using a vapor pressure osmometer (model 5500; Wescor, Logan, Utah). Two leaves from each plant were sampled and two sub-samples were tested from each leaf. Osmotic potential of the expressed sap was then calculated based on the van't Hoff relation reported by Nobel (1983). Although this method may result in some dilution of symplastic solutes due to apoplastic water, Lakso et al. (1984) found little difference in osmotic potential between expressed sap and the values determined using the pressure volume method.

CARBOHYDRATE anALYSIS. Recently matured leaves were removed from the plants in early morning and immediately frozen at $-80^{\circ} \mathrm{C}$. Frozen leaf tissue was lyophilized and ground to pass a 40 -mesh $(0.635 \mathrm{~mm})$ screen. For each plant sample, $200 \mathrm{mg}$ of ground tissue was placed in a 15 -mL centrifuge tube and suspended in $3 \mathrm{~mL}$ of $80 \%$ aqueous ethanol. The slurry was incubated at 80 ${ }^{\circ} \mathrm{C}$ for $5 \mathrm{~min}$ then centrifuged at $1000 g_{\mathrm{n}}$ for $10 \mathrm{~min}$. The extraction was repeated two more times with the supernatant combined after each. Pooled extracts were evaporated at $45^{\circ} \mathrm{C}$ under vacuum and oven dried over night at $70^{\circ} \mathrm{C}$. The residue was dissolved in 1.0 $\mathrm{mL}$ of deionized, distilled water and soluble sugars analyzed by HPLC. The HPLC system (described by Prata et al., 1997) was equipped with a guard column (C-18 Corasil; Bio-Rad, Hercules, Calif.) and in-line cation and anion guards (Micro-Guard, Bio$\mathrm{Rad})$. Carbohydrates were separated on a column $\left(\mathrm{Pb}^{++}\right.$Carbohydrate column, Sierra Separations, Sparks, Nev.) with a flow rate of $0.4 \mathrm{~mL} \cdot \mathrm{min}^{-1}$ water at $75^{\circ} \mathrm{C}$. Carbohydrate identity and quantity were analyzed using a differential refractometer (model 410; Waters/Millipore, Milford, Mass.) coupled to a computing integrator (model SP4200; Spectra Physics, San Jose, Calif.), and compared with carbohydrate standards.

EXPERIMENTAL DESIGN. The experimental design was a randomized complete block design with a split-plot arrangement of treatments, replicated seven times. Irrigation regimes were treated as whole plots, with subplots consisting of plant ecotypes. Pn and WUE data during initial substrate dry-down were analyzed using regression analysis. Temperature response and $\mathrm{A} / \mathrm{Ci}$ curves were analyzed as a split-split-plot with temperature and $\mathrm{Ci}$ as the sub-subplots, respectively. Data were subjected to ANOVA, and a cubic regression was the best fit for each temperature response 


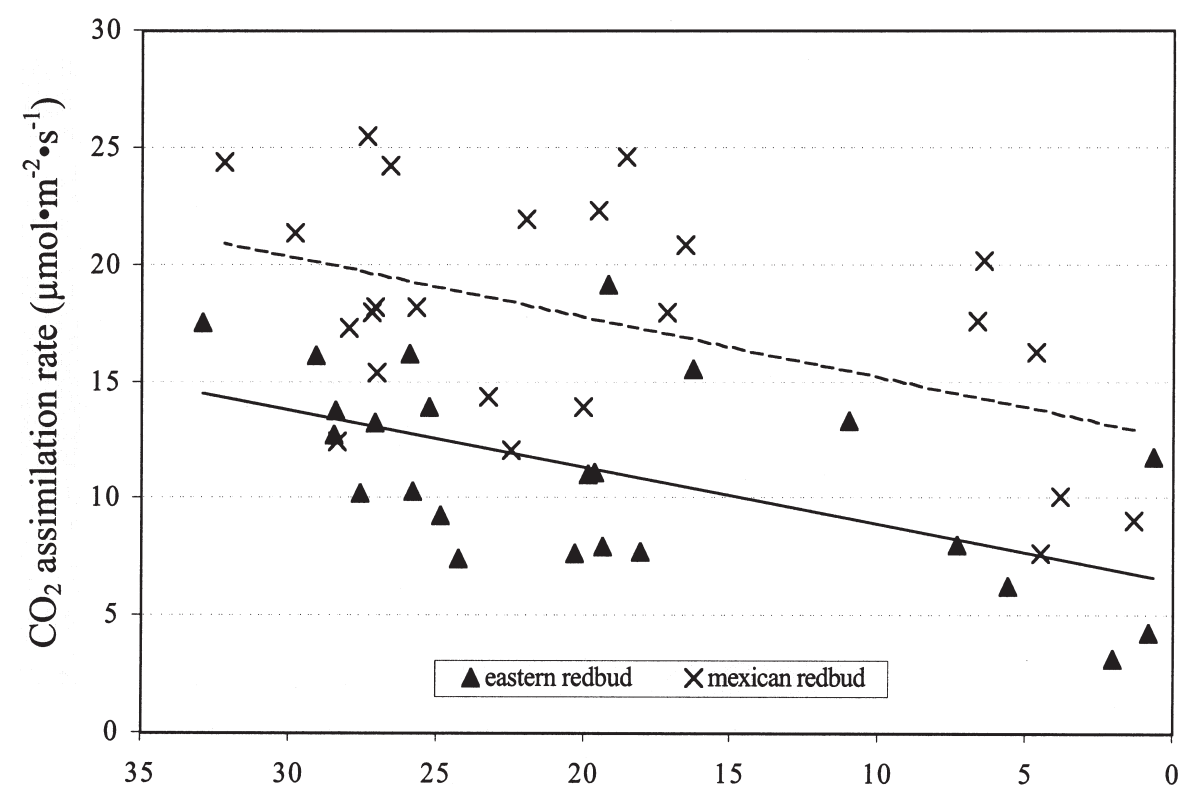

Substrate water content ( $\%$ of vol.)
Fig. 1. Photosynthesis of mexican redbud and eastern redbud during container substrate drying at $350 \mu \mathrm{L} \cdot \mathrm{L}^{-1}$ $\mathrm{CO}_{2}$ and $2000 \mu \mathrm{mol} \cdot \mathrm{m}^{-2} \cdot \mathrm{s}^{-1} P A R$. Linear regression fit to mexican redbud (broken line, $\mathrm{y}=0.23 \mathrm{x}+12.7, r^{2}=$ 0.24 ) and eastern redbud (solid line, $\mathrm{y}=0.24 \mathrm{x}+6.5, r^{2}$ $=0.32$ ).

than the drought stressed plants (34.3 and 23.2 $\mu \mathrm{mol} \cdot \mathrm{m}^{-2} \cdot \mathrm{s}^{-1}$, respectively), and the Mexican ecotype had a higher rate per unit area than the eastern ecotype $\left(33.0\right.$ and $24.5 \mu \mathrm{mol} \cdot \mathrm{m}^{-2} \cdot \mathrm{s}^{-1}$, respectively).

The $\mathrm{A} / \mathrm{Ci}$ response curves were used to evaluate the effects of drought on specific nonstomatal limitations to the carbon exchange rate (Fig. 4). The estimated maximum rate of photosynthesis $\left(\mathrm{A}_{\max }\right)$, carboxylation efficiency (CE), and respiration in the light $\left(\mathrm{R}_{\mathrm{L}}\right)$ were determined for $30^{\circ} \mathrm{C}$. However, few measurements could be taken above saturating levels of $\mathrm{CO}_{2}$ in the water-stressed plants due to low stomatal conductance. As a result, the model provided a poor fit to the data and predicted much higher rates of $A_{\max }$ than were observed.

curve. The A/Ci model was fit to the data using the Proc NLIN feature in SAS (Cary, N.C.). The osmotic potential and the soluble carbohydrate data were also analyzed as a split-plot, and were subjected to ANOVA. Where appropriate, means were separated with a protected LSD at $P \leq 0.05$ (SAS Institute, Cary, N.C.).

\section{Results}

After the final irrigation event, it took $14 \mathrm{~d}$ for the substrate water content of drought stressed plants to decrease to $2 \%$ to $5 \%$. During that time, Pn decreased linearly with decreasing substrate water content, with a significant $(P \leq 0.05)$ main effect of ecotype (Fig. 1). There was no interaction, suggesting the response to substrate drying was similar between the ecotypes. Similarly, WUE of both ecotypes decreased linearly, with no significant interaction, in response to drought (Fig. 2).

To investigate how drought influenced the temperature optimum for potential photosynthetic capacity, temperature response curves were generated at saturating light and $\mathrm{CO}_{2}$ concentration (Fig. 3). A three-way interaction occurred between the irrigation regime, ecotype, and temperature. The temperature optimum for maximum photosynthesis of both ecotypes was estimated using the cubic function to be $37{ }^{\circ} \mathrm{C}$ and was unaffected by drought. The main effects of irrigation regime and ecotype, however, were significant $(P \leq 0.05)$ for maximum photosynthetic capacity, but there was no interaction (Fig. 3). When ecotype and irrigation regime were compared at the optimum temperature, watered plants had higher rates of assimilation

Fig. 2. Instantaneous water use efficiency (WUE) (net photosynthesis/transpiration) of mexican redbud and eastern redbud during substrate drying. Linear regression fit to both ecotypes; mexican redbud (broken line, $\mathrm{y}=0.03 \mathrm{x}+3.1, r^{2}=0.19$ ) eastern redbud (solid line, $\left.\mathrm{y}=0.02 \mathrm{x}+2.2, r^{2}=0.14\right)$.

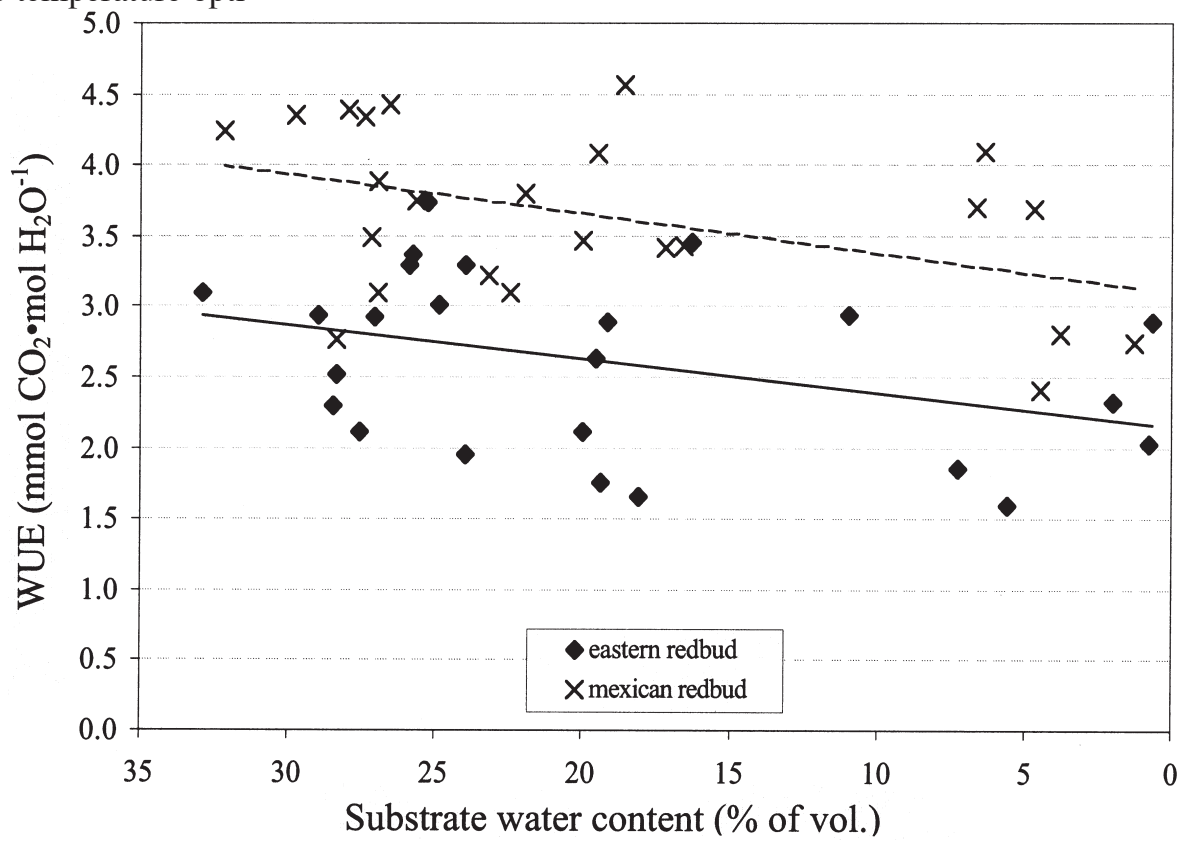

In a similar scenario, Escalona et al. (1999) used the rate of photosynthesis at the highest level of $\mathrm{CO}_{2}$ to represent $\mathrm{A}_{\max }$. Using this method, we observed a significant main effect of irrigation and ecotype on $\mathrm{A}_{\max }$. Irrigated plants had a significantly higher $\mathrm{A}_{\max }$ than the drought-stressed plants $\left(24.9\right.$ and $16.4 \mu \mathrm{mol} \cdot \mathrm{m}^{-2} \cdot \mathrm{s}^{-1}$, respectively), and mexican redbud had a slightly higher $\mathrm{A}_{\max }$ than eastern redbud (21.6 and $19.3 \mu \mathrm{mol} \cdot \mathrm{m}^{-2} \cdot \mathrm{s}^{-1}$, respectively). There were no differences in CE or $\mathrm{R}_{\mathrm{L}}$ among the ecotypes or treatments (data not presented).

Tissue osmotic potential was significantly lower (more negative) in eastern redbud than mexican redbud $(-1.4 \pm 0.06$ and -1.0 $\pm 0.03 \mathrm{MPa}$, respectively, $\mathrm{n}=14)$, but was unaffected by water regime in both ecotypes (i.e., there was no osmotic adjustment). D-pinitol was the primary soluble carbohydrate occurring in the leaves of both ecotypes also (Table 1.). Sucrose was the other substantial soluble carbohydrate, and its content was reduced 


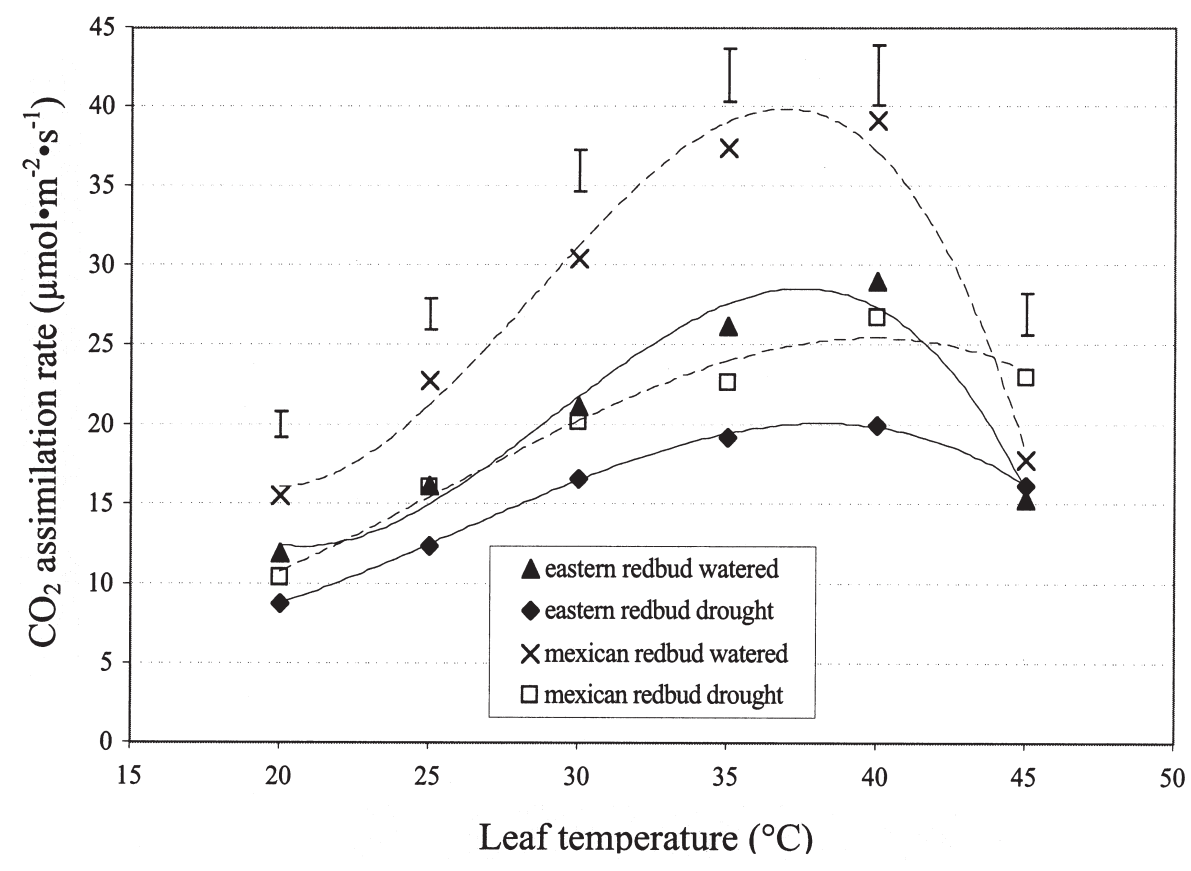

by drought in both ecotypes. Smaller contributions to the total soluble carbohydrates came from glucose, fructose, myo-inositol and ononitol. The dominance of pinitol is clear as its content is more than 2-fold greater than the other carbohydrates combined. The content of D-pinitol was greater in drought-stressed plants than well-watered plants and was higher in eastern redbud than mexican redbud. However, there was no interaction between ecotype and water regime, suggesting the changes in D-pinitol content between the ecotypes responded similarly to water stress. If the polyols with putative roles as compatible solutes and free radical scavengers are summed (myo-inositol + ononitol + pinitol), their content was significantly increased from the watered plants to the water stressed plants (1605 vs. $2439 \mu \mathrm{g} \cdot \mathrm{g}^{-1}$ dry weight, respectively). The percent increase, however, was greater for the Mexican ecotype than the eastern ecotype (62\% and $40 \%$, respectively) even though the absolute values were higher in the eastern redbud. Data were also analyzed on a fresh weight basis in case there were any differences in leaf water content. Similar treatment effects were observed with similar trends and relative changes among treatments (data not presented).

\section{Discussion}

Net photosynthesis of both ecotypes responded in a similar manner to increasing drought (Fig. 1). Mexican redbud maintained greater Pn as substrate water content declined and this may have resulted from greater leaf thickness and other morphological factors typical of the ecotype (Donselman and Flint, 1982). Our observations from a random sample of leaves taken indicated that leaves

Fig. 4. Photosynthesis of typical irrigated and drought stressed mexican redbud and eastern redbud during increasing intercellular $\mathrm{CO}_{2}$ concentrations. Model was fit to irrigated plants only; mexican redbud, broken line, $r^{2}=0.98$; eastern redbud, solid line, $r^{2}=0.99$.
Fig. 3. Potential photosynthetic capacity with cubic regression fit to irrigated and drought stressed mexican redbud (broken line); $y=-0.0097 \mathrm{x}^{3}+0.8297 \mathrm{x}^{2}-21.47 \mathrm{x}+$ $191.44, r^{2}=0.98$ and $\mathrm{y}=-0.0017 \mathrm{x}^{3}+0.1275 \mathrm{x}^{2}-2.2931 \mathrm{x}$ $+18.771, r^{2}=0.97$, respectively, and eastern redbud (solid line); $\mathrm{y}=-0.0069 \mathrm{x}^{3}+0.6064 \mathrm{x}^{2}-16.206 \mathrm{x}+149.46, r^{2}=$ 0.97 and $y=-0.002 x^{3}+0.1552 x^{2}-3.2596 x+27.595$, $r^{2}=0.99$, respectively, during increasing temperature at $2000 \mu \mathrm{L} \cdot \mathrm{L}^{-1} \mathrm{CO}_{2}$ and $2000 \mu \mathrm{mol} \cdot \mathrm{m}^{-2} \cdot \mathrm{s}^{-1} P A R, \mathrm{n}=7$. Error bars represent \pm 1 SE of all data collected at that temperature, $\mathrm{n}=28$.

of the Mexican redbud may have been $\approx 30 \%$ thicker than leaves of the eastern redbud (data not presented). Increased volume per unit leaf area might account for much of the observed differences between the ecotypes, but further research is required to confirm this point. Mexican redbud also had higher WUE throughout the drying cycle (Fig. 2), indicating that, per unit leaf area, this ecotype can assimilate more carbon per mole of water transpired - a beneficial trait for plants growing in arid climates. The higher WUE for mexican redbud might also have resulted from greater leaf thickness.

Numerous studies have found that drought can compromise the thermotolerance of Pn and reduce the capacity of photosynthetic processes to acclimate to high temperatures (Briggs et al., 1986; Nobel et al., 1978; Smolander and Lappi, 1984). Redbuds, however, do not appear to follow that trend. In the current study, $37^{\circ} \mathrm{C}$ was the optimum temperature for potential photosynthetic capacity $\left(\mathrm{CO}_{2}\right.$ saturated) regardless of ecotype or water regime (Fig. 3). These data would suggest that the physiological and biochemical mechanisms of photosynthesis in these two ecotypes responded similarly to increasing temperature.

At the optimum temperature of $37^{\circ} \mathrm{C}$, both ecotype and irrigation affected the maximum rate of assimilation. Potential photosynthetic capacity was much greater in watered plants than drought stressed plants, indicating that water deficits inhibited photosynthetic processes independent of limitations due to

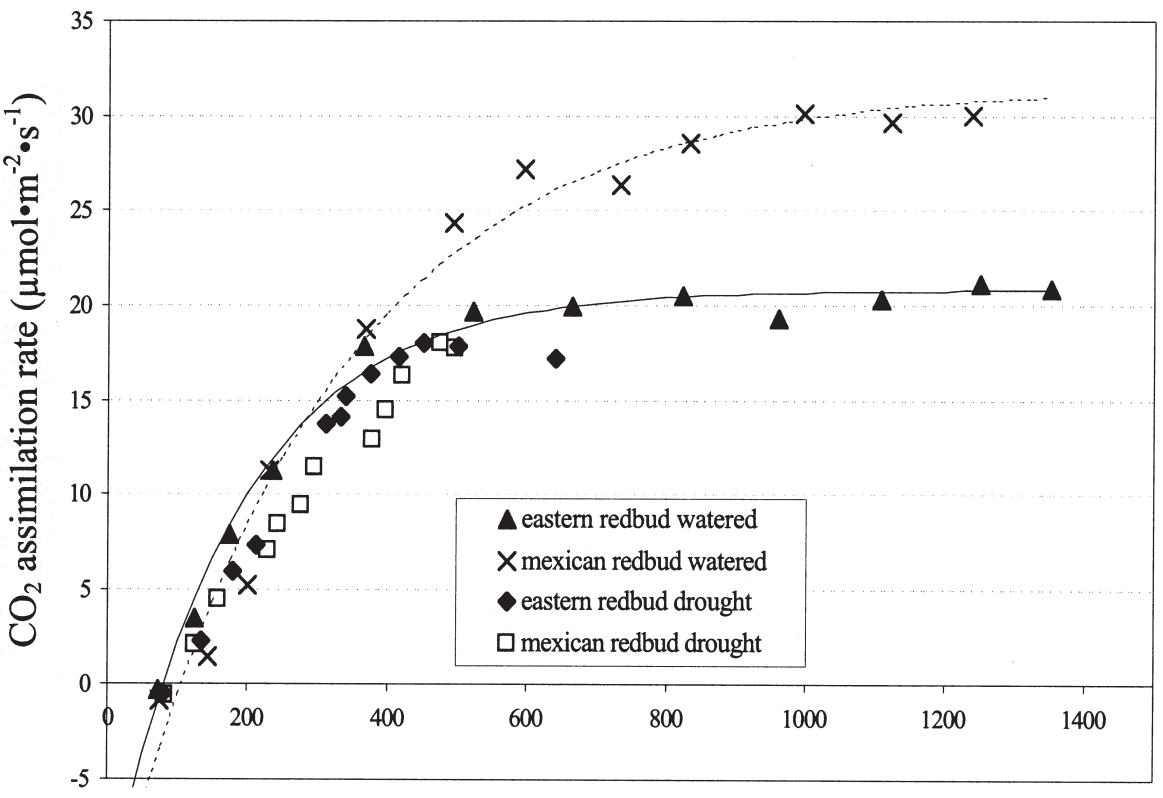

Intercellular $\mathrm{CO}_{2}$ concentration $\left(\mu \mathrm{L} \cdot \mathrm{L}^{-1}\right)$ 
Table 1. Soluble carbohydrate content of leaf tissue $(\mu \mathrm{g} \cdot \mathrm{g}-1$ dry weight) from two ecotypes of redbud (Cercis canadensis) grown under well watered or drought conditions.

\begin{tabular}{lcccc}
\hline & \multicolumn{2}{c}{ Cercis canadensis var. canadensis } & \multicolumn{2}{c}{ Cercis canadensis var. mexicana } \\
\cline { 2 - 4 } Carbohydrate & Watered & Drought & Watered & Drought \\
\hline Sucrose & $950 \mathrm{a}^{\mathrm{z}}$ & $551 \mathrm{~b}$ & $\mathrm{a}$ & 195 \\
Glucose & 41 & 56 & 201 & 131 \\
Fructose & 111 & 201 & 63 & 222 \\
Myo-inositol & 57 & 91 & 75 & 76 \\
Ononitol & 103 & 45 & $1206 \mathrm{~b}$ & $2011 \mathrm{a}$ \\
Pinitol & $1793 \mathrm{~b}$ & $2603 \mathrm{a}$ & $222 \mathrm{~b}$ & $2712 \mathrm{a}$ \\
Total & $3055 \mathrm{~b}$ & $3547 \mathrm{a}$ & & \\
\hline
\end{tabular}

${ }^{2}$ Mean separation within a row and within a taxon by Fisher's protected LSD $(P \leq 0.05) ; \mathrm{n}=7$. Values followed by a similar letter are not significantly different. If there are no letters in the row, ANOVA indicated no treatment effects.

stomatal conductance (Figs. 3 and 4). Reduced photosynthetic capacity during drought can be an indication of photoinhibition (Osonubi and Davies, 1980) or direct effects of dehydration on photosynthetic processes (Kaiser, 1987).

Accumulation of various osmolytes in drought stressed plants is common (see reviews by Hare et al., 1998; Popp and Smirnoff, 1995). In redbuds, however, the osmotic potential at full turgor was unaffected by drought conditions. Ecotype was the only factor influencing the osmotic potential at full turgor, with eastern redbud significantly lower than mexican redbud ( -1.4 and -1.0 $\mathrm{MPa}$, respectively). Despite this, both ecotypes accumulated considerable amounts of D-pinitol. The occurrence, accumulation, and potential physiological roles of D-pinitol have been well studied in soybeans [Glycine $\max (\mathrm{L}$.$) Merr.], and pinitol is a common$ sugar alcohol in many legumes (Guo and Oostrhuis, 1995, 1997; Kuo et al., 1997; Smith and Phillips, 1982). This, however, is the first reported quantification of foliar soluble carbohydrates in redbud that demonstrates the substantial concentration of pinitol. The role of pinitol and its precursors (myo-inositol and ononitol) as osmoprotectants or compatible solutes has been well studied in the halophyte common ice plant (Mesembryanthemum crystallinum L.), and its induction by salt and drought treatment has been well established (Paul and Cockburn, 1989; Vernon and Bohnert, 1992a, 1992b). Additionally, the putative antioxidant capabilities of these polyols may prove to have greater ecophysiological significance than the osmotic role. The amount of pinitol produced by redbuds might confer some level of tolerance to the production of free oxygen radicals. In this study, the sum of all the polyols (myo-inositol + ononitol + pinitol) was increased in response to drought, with no indication of any osmotic adjustment at full turgor. Although the total accumulation was greater in the eastern redbud, the increase relative to the watered plants was greater in the mexican redbud. This accumulation of putative osmoprotectants and antioxidants might represent a physiological response to drought and a mechanism to protect against photoinhibition.

Both ecotypes were extremely drought and heat tolerant in this study. It was not surprising with the Mexican ecotype but unexpected for the eastern redbud. In a recent examination of the molecular taxonomy of redbuds, Davis et al. (2002) proposed that eastern redbud and mexican redbud are related through a common xerophytic ancestor, and eastern redbud represents a "mesophytic reversion" of a xerophytic form. Thus, despite the fact that eastern redbud is typically found in more temperate, mesophytic environments, it could have retained certain xerophytic characteristics, providing competitive advantages in dry woodlands understory, ridge top, and rock outcrop habitats where it is often found. If this scenario is correct, it could explain why, in the current study, eastern redbud proved to be very heat and drought tolerant, and responded similarly, in many respects, to the xerophytic mexican redbud.

\section{Literature Cited}

Berkowitz, G.A. 1998. Water and salt stress, p. 226-237. In:A.S. Raghavendra (ed.). Photosynthesis: Acomprehensive treatise. Cambridge Univ. Press, Cambridge, U.K.

Berry, J. and O. Björkman. 1980. Photosynthetic response and adaptation to temperature in higher plants. Annu. Rev. Plant Physiol. 31: 491-553.

Biswal, B. 1997. Chloroplasts, pigments, and molecular responses of photosynthesis under stress, p. 877-885. In: M. Pessarakli (ed.). Handbook of photosynthesis. Marcel Dekker, New York.

Briggs, G.M., T.W. Jurik, and D.M. Gates. 1986. Non-stomatal limitation of $\mathrm{CO}_{2}$ assimilation in three tree species during natural drought conditions. Physiol. Plant. 66:521-526.

Crafts-Brandner, S.J. and R.D. Law. 2000. Effect of heat stress on the inhibition and recovery of the ribulose-1,5-bisphosphate carboxylase/ oxygenase activation state. Planta 212:67-74.

Crafts-Brandner, S.J. and M.E. Salvucci. 2000. Rubisco activase constrains the photosynthetic potential of leaves at high temperature and $\mathrm{CO}_{2}$. Proc. Natl. Acad. Sci. USA 97:13430-13435.

Davis, C.C., P.W. Fritsch, J. Li, and M.J. Donoghue. 2002. Phylogeny and biogeography of Cercis (Fabaceae): Evidence from nuclear ribosomal ITS and chloroplast $n d h F$ sequence data. Syst. Bot. 27:289-302.

Donselman, H.M. and H.L. Flint. 1982. Genecology of eastern redbud (Cercis canadensis). Ecology 63:962-971.

Dubey, R.S. 1997. Photosynthesis in plants under stressful conditions, p. 859-875. In: M. Pessarakli (ed.). Handbook of photosynthesis. Marcel Dekker, New York.

Escalona, J.M., J. Flexas, and H. Medrano. 1999. Stomatal and nonstomatal limitation of photosynthesis under water stress in field-grown grapevines. Austral. J. Plant Physiol. 26:421-433.

Evans, R.D., R.A. Black, and S.O. Link. 1990. Rehydration-induced changes in pressure-volume relationships of Artmisia tridentata Nutt. Ssp. tridentata. Plant, Cell Environ. 13:455-461.

Falk, S., D.P. Maxwell, D.E. Laudenbach, and N.P.A. Huner. 1996. Photosynthetic adjustment to temperature, p. 367-385. In: N.R. Baker(ed.). Advances in photosynthesis: Photosynthesis and the environment. vol. 5. Kluwer Academic Publishers, The Netherlands.

Guo, C. and D.M. Oosterhuis. 1995. Pinitol occurrence in soybean plants as affected by temperature and plant growth regulators. J. Expt. Bot. 46:249-253.

Guo, C. and D.M. Oosterhuis. 1997. Effect of water-deficit stress and genotypes on pinitol occurrence in soybean plants. Environ. Expt. Bot. 37:147-152.

Hale, M.G. and D.M. Orcutt. 1987. The physiology of plants under stress. Wiley, New York.

Hare, P.D., W.A. Cress, and J. Van Staden. 1998. Dissecting the roles of os- 
molyte accumulation during stress. Plant Cell Environ. 21:535-53.

Jacob, J., C. Greitner, and B.G. Drake. 1995. Acclimation of photosynthesis in relation to Rubisco and non-structural carbohydrate contents and in situ carboxylase activity in Scirpus olneyi at elevated $\mathrm{CO}_{2}$ in the field. Plant, Cell Environ. 18:875-884.

Kaiser, W.M. 1987. Effects of water deficit on photosynthetic capacity. Physiol. Plant. 71:142-149.

Krüger, G.H.J and L. van Rensburg. 1995. Carbon dioxide fixation: Stomatal and non-stomatal limitation in drought-stressed Nicotiana tabacum L. cultivars, p. 505-510. In: P. Mathis (ed.). Photosynthesis: From light to biosphere. vol 4. Kluwer Academic Publishers, Dordrecht, The Netherlands.

Kuo, T.M., C.A. Lowell, and T.C. Nelsen. 1997. Occurrence of pinitol in developing soybean seed tissues. Phytochemistry 45:29-35

Lakso, A.N., A.S. Geyer, and S.G. Carpenter. 1984. Seasonal osmotic relations in apple leaves of different ages. J. Amer. Soc. Hort. Sci. 109:544-547.

Lichtenthaler, H.K. 1996. Vegetation stress: An introduction to the stress concept in plants. J. Plant. Physiol. 48:4-14.

Mahan, J.R., B.L. McMichael, and D.F. Wanjura. 1997. Reduction of high temperature stress in plants, p. 137-150. In: A.S. Basra and R.K. Basra (eds.). Mechanisms of environmental stress resistance in plants. Harwood Academic Publishers, The Netherlands.

McManus, M.T., R.L. Bieleski, J.R. Caradus, and D.J. Barker. 2000. Pinitol accumulation in mature leaves of white clover in response to a water deficit. Environ. Expt. Bot. 43:11-18.

Nobel, P.S. 1983. Biophysical plant physiology and ecology. Freeman, New York.

Nobel, P.S., D.J. Longstreth, and T.L. Hartsock. 1978. Effect of water stress on the temperature optima of net $\mathrm{CO}_{2}$ exchange for two desert species. Physiol. Plant. 44:97-101.

Osonubi, O. and W.J. Davies. 1980. The influence of water stress on the photosynthetic performance and stomatal behavior of tree seedlings subjected to variation in temperature and irradiance. Oecologia 45:3-10.

Paul, M.J. and W. Cockburn. 1989. Pinitol, a compatible solute in $\mathrm{Me}$ sembryanthemem crystallinium L.? J. Expt. Bot. 40:1093-1098.

Popp, M. and N. Smirnoff. 1995. Polyol accumulation and metabolism during water deficit, p. 199-215. In: N. Smirnoff (ed.). Environment and plant metabolism: Flexibility and acclimation. BIOS Scientific Publ., Oxford, U.K.

Prata, R.T.N., J.D. Williamson, M.A. Conkling, and D.M. Pharr. 1997. Sugar repression of mannitol dehydrogenase activity in celery cells.
Plant Physiol. 114:307-314.

Ranney, T.G., N.L. Bassuk, and T.H. Whitlow. 1991. Osmotic adjustment and solute constituents in leaves and roots of water-stressed cherry (Prunus) trees. J. Amer. Soc. Hort. Sci. 116:684-688.

Ranney, T.G. and M.M. Peet. 1994. Heat tolerance of five taxa of birch (Betula): Physiological response to supraoptimal leaf temperatures. J. Amer. Soc. Hort. Sci. 119:243-248.

Ranney, T.G. and J.M. Ruter. 1997. Foliar heat tolerance of three holly species (Ilex spp.): Responses of chlorophyll fluorescence and leaf gas exchange to supraoptimal leaf temperatures. J. Amer. Soc. Hort. Sci. 122:499-503.

Reid, C.D. and E.L. Fiscus. 1998. Effects of elevated $\left[\mathrm{CO}_{2}\right]$ and/or ozone on limitations to $\mathrm{CO}_{2}$ assimilation in soybean (Glycine max). J. Expt. Bot. 49:885-895.

Shen, B., R.G. Jensen, and H.J. Bohnert. 1997. Increased resistance to oxidative stress in transgenic plants by targeting mannitol biosynthesis to chloroplasts. Plant Physiol. 113:1177-1183.

Sheveleva, E., W. Chmara, H.J. Bohnert, and R.G. Jensen. 1997. Increased salt and drought tolerance by D-ononitol production in transgenic $\mathrm{Ni}$ cotiana tabacum L. Plant Physiol. 115:1211-1219.

Smirnoff, N. and Q.J. Cumbes. 1989. Hydroxyl radical scavenging activity of compatible solutes. Phytochemistry 28:1057-1060.

Smith, A.E. and D.V. Phillips. 1982. Influence of sequential prolonged periods of dark and light on pinitol concentration in clover and soybean tissue. Physiol. Plant 54:31-33.

Smolander, H. and J. Lappi. 1984. The interactive effect of water stress and temperature on the $\mathrm{CO}_{2}$ response of photosynthesis in Salix. Silva Fennica 18:133-139.

Stoyanova, D. and I. Yordanov. 1999. Influence of drought, high temperature, and carbamide cytokinin 4-PU-30 on photosynthetic activity of plants. 2. Chloroplast ultrastructure of primary bean leaves. Photosynthetica 37:621-625.

Thomas, H. 1997. Drought resistance in plants, p. 1-42. In: A.S. Basra and R.K. Basra (eds.). Mechanisms of environmental stress resistance in plants. Harwood Academic Publ., The Netherlands.

Vernon, D.M. and H.J. Bohnert. 1992a. Anovel methyl transferase induced by osmotic stress in the facultative halophyte Mesembryanthemum crystallinum. EMBO J. 11:2077-2085.

Vernon, D.M. and H.J. Bohnert. 1992b. Increased expression of a myoinositol methyl transferase in Mesembryanthemum crystallinum is part of a stress response distinct from crassulacean acid metabolism induction. Plant Physiol. 99:1695-1698. 